\title{
UV-Cured Coatings Prepared with Sulfhydryl-Terminated Branched Polyurethane and Allyl-Terminated Hyperbranched Polycarbosilane
}

\author{
Xiaojiao Jiao ${ }^{1}$, Taixu Zhang ${ }^{2}$, Fei Cheng ${ }^{1}$, Yunxin Fan ${ }^{1}$, Jiangling Liu ${ }^{1}$, Guoqiao Lai ${ }^{1, *}$, \\ Yufei $\mathrm{Wu}^{1}$ and Xiongfa Yang ${ }^{1, *(D)}$ \\ 1 Key Laboratory of Organosilicon Chemistry and Material Technology of Education Ministry, Hangzhou \\ Normal University, Hangzhou 311121, Zhejiang, China; jiaojiao96126@163.com (X.J.); \\ cf123333@163.com (F.C.); 15933726811@163.com (Y.F.); ljlcaitlyn@163.com (J.L.); \\ wuyufei@stu.hznu.edu.cn (Y.W.) \\ 2 Xinyaqiang Silicone Chemical Co., Ltd, Suqian 223809, Jiangsu, China; ztx0325@163.com \\ * Correspondence: laiguoqiao@aliyun.com (G.L.); yangxiongfa@163.com (X.Y.)
}

Received: 20 February 2020; Accepted: 27 March 2020; Published: 3 April 2020

\begin{abstract}
The conventional polyurethane (PU) coatings have poor heat resistance, which will undergo severe pyrolysis when the temperature exceeds $200{ }^{\circ} \mathrm{C}$. To overcome the shortcoming of conventional PU coatings, an ultraviolet (UV)-cured solvent-free hyperbranched polycarbosilane modified PU coatings was prepared by sulfhydryl-terminated polyurethane and allyl-terminated hyperbranched polycarbosilane. The initial decomposition temperature $\left(\mathrm{T}_{\mathrm{d}} 5 \%\right)$ of the UV-cured coating ranges from 258 to $268^{\circ} \mathrm{C}$, which is obviously higher than those of the conventional PU coatings reported. The coating shows fairly low water absorption in the range of $0.6-1.36 \mathrm{wt} \%$ and exhibits grade 1 , grade 2 and grade 3 adhesion to glass, tin plate and aluminum sheet, respectively.
\end{abstract}

Keywords: UV cured coating; silicone modified polyurethane; hyperbranched polycarbosilane; thermal stability

\section{Introduction}

Ultraviolet (UV)-cured coatings have drawn much attention because of their advantages such as environment friendliness, rapid curing rates, and optimized energy consumption [1-6]. UV-cured polyurethane (PU) is widely used in coatings to improve the appearance, lifespan, and corrosion resistance of products [7-9]. However, the conventional PU coatings, namely PUs synthesized via diisocyanates and polyols with various chain length, have poor heat resistance, which will undergo severe pyrolysis when the temperature exceeds $200{ }^{\circ} \mathrm{C}$ [9-11]. The poor mechanical performance and chemical resistance of conventional PU coatings attributed to the low density and inadequate photosensitive groups of the PU oligomers also limit the application of PU coatings [12]. Therefore, efforts should be made to develop novel PUs coatings with superior performances.

Polycarbosilanes are a class of polymers at the interface between organic and inorganic chemistry; the $\mathrm{Si}-\mathrm{C}$ bond of carbosilane is less susceptible to nucleophilic attack than the $\mathrm{Si}-\mathrm{O}$ bonds in siloxanes, which is part attributed to the relative stability of the carbosilane [13]. The crosslinkable carbosilane polymers exhibit excellent heat-resistance [14,15]. Inspired by these works, a polyurethane coating might be modified with polycarbosilanes to improve heat resistance.

Hyperbranched polymers have attracted much attention in the field of UV-curable coatings because of their low viscosity, highly branched structure, and rich functional moieties and many experiments have confirmed that the application of hyperbranched polymers in a UV-curable coating can reduce the content of reactive diluent and solvent, which can reduce the emission of $\mathrm{V}^{\circ} \mathrm{C}[13,16-18]$. 
Hyperbranched polycarbosilane has both the advantages of polycarbosilane and hyperbranched polymers [17].

The aim of this work is to fabricate a UV-cured solvent-free hyperbranched polycarbosilane modified PU coating. The UV-cured silicone coatings were prepared by sulfhydryl terminated polyurethanes and allyl terminated hyperbranched polycarbosilanes. The thermal stability, hardness, adhesion property, water absorption, surface water contact angle and corrosion resistance to acid, alkali and salt were also explored. The results confirmed that the UV-cured coatings obtained have fairly high thermal stability, low water absorption, and good adhesion to glass.

\section{Materials and Methods}

\subsection{Materials}

The materials used are summarized in Table 1.

Table 1. The materials used.

\begin{tabular}{|c|c|c|}
\hline Materials & Suppliers & Remarks \\
\hline Polyether diol (PPG-2000, Mn = 2000, A.R.) & $\begin{array}{l}\text { 9dingchem (Shanghai) Chemical } \\
\text { Co., Ltd. }\end{array}$ & $\begin{array}{l}\text { Distilled at } 110^{\circ} \mathrm{C} \text { under } 120^{\circ} / 130 \\
\text { mmHg for } 1 \mathrm{~h} \text { before used. }\end{array}$ \\
\hline $\begin{array}{l}\text { Isophorone diisocyanate (IPDI, A.R.) } \\
\text { 2,2-Bis(hydroxymethyl)propionic acid } \\
\text { (DMPA, A.R.) }\end{array}$ & $\begin{array}{l}\text { Energy Chemical (Shanghai) } \\
\text { Chemical Co., Ltd. }\end{array}$ & / \\
\hline $\begin{array}{l}\text { Trimethylolpropane tris(thioglycolate) } \\
\text { (TTMA, A.R.) }\end{array}$ & Tokyo Chemical Industry Co., Ltd. & / \\
\hline Methyl trimethoxysilane (C.P.) & Shanghai Jiancheng Industry and & l \\
\hline Methyltrichlorosilane (C.P.) & Trade Co., Ltd. & 1 \\
\hline Ether (A.R.) & Beijing HWRK Chem Co., Ltd. & $\begin{array}{l}\text { Distilled over potassium before } \\
\text { used. }\end{array}$ \\
\hline tetrahydrofuran (A.R.) & & $\begin{array}{l}\text { Distilled over potassium before } \\
\text { used. }\end{array}$ \\
\hline $\begin{array}{c}\text { HydroChloric acid ( } 36.5 \%, \text { A.R.) } \\
\text { Ditin butyl dilaurate (DBTDL, A.R.) } \\
\text { sodium chloride (A.R.) } \\
\text { ammonium chloride (A.R.) } \\
\text { magnesium sulfate anhydrous (A.R.) } \\
\text { toluene (A.R.) }\end{array}$ & $\begin{array}{l}\text { Sinopharm Chemical Reagent Co., } \\
\text { Ltd., China. }\end{array}$ & 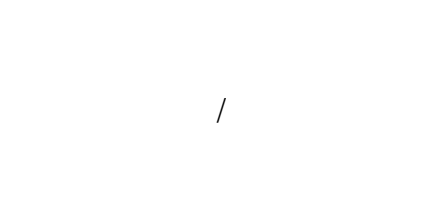 \\
\hline Magnesium powder (A.R.) & $\begin{array}{l}\text { Shanghai Lingfeng Chemical } \\
\text { Reagent Co., Ltd. }\end{array}$ & l \\
\hline 3-Bromopropene (A.R.) & $\begin{array}{c}\text { Adamas Reagent Co., Ltd. } \\
\text { (Shanghai) }\end{array}$ & / \\
\hline iodine (A.R.) & $\begin{array}{l}\text { TCI (Shanghai) Chemical } \\
\text { Industrial Development Co., Ltd. }\end{array}$ & / \\
\hline Platinum catalyst & Prepared by our group & The content of $\mathrm{Pt}$ is $8000 \mathrm{ppm}$ \\
\hline
\end{tabular}

\subsection{Preparation of Sulfhydryl-Terminated Polyurethanes (Sulf-PUs)}

The sulfhydryl-terminated polyurethanes (sulf-PUs) were synthesized according to Scheme $1[19,20]$ and the raw materials feed ratios were collected in Table 2 . To a typical procedure for synthesize sulf-PU-4 in Table 2, $22.22 \mathrm{~g}$ IPDI $(0.1 \mathrm{~mol})$ and $1.34 \mathrm{~g}$ DMPA $(0.01 \mathrm{~mol})$ were added into a $500 \mathrm{~mL}$ three-necked flask. Subsequently, $20.00 \mathrm{~g}$ PPG-2000 (0.01 mol) was dripped slowly into the three-necked flask for about $30 \mathrm{~min}$ and then $0.17 \mathrm{~g}$ DBTDL was added. The mixture was kept at $60{ }^{\circ} \mathrm{C}$ for $3 \mathrm{~h}$ and then $90 \mathrm{~mL}$ tetrahydrofuran was added into it. Then, the mixture was introduced into a mixture of $57.02 \mathrm{~g}$ TTMA $(0.16 \mathrm{~mol})$ and $57.02 \mathrm{~g}$ tetrahydrofuran at $40^{\circ} \mathrm{C}$ for about $2 \mathrm{~h}$. Later, the mixture was heated to $65^{\circ} \mathrm{C}$ and reacted for $3 \mathrm{~h}$. Finally, the residuals of the raw materials and tetrahydrogen were removed by a rotary evaporator and a pale yellow viscous solid product of sulf-PU-4 was obtained. Because the reaction for synthesis of sulf-PU was not selective, the products obtained are mixtures of polyurethanes end-capped with multiple sulfhydryl groups. Fourier-transform infrared (FT-IR) spectroscopic analysis of sulf-PU-4 was conducted as shown in 
Figure S1. The characteristics absorption at $2530-2590 \mathrm{~cm}^{-1}$ was ascribed to $-\mathrm{SH}$. Obviously, there are no characteristic absorption of isocyanate group and $\mathrm{OH}$ of polyether in the range of $2260-2280 \mathrm{~cm}^{-1}$ and $3500 \mathrm{~cm}^{-1}$ respectively, which denotes that the isocyanate group and $-\mathrm{OH}$ reacted completely.

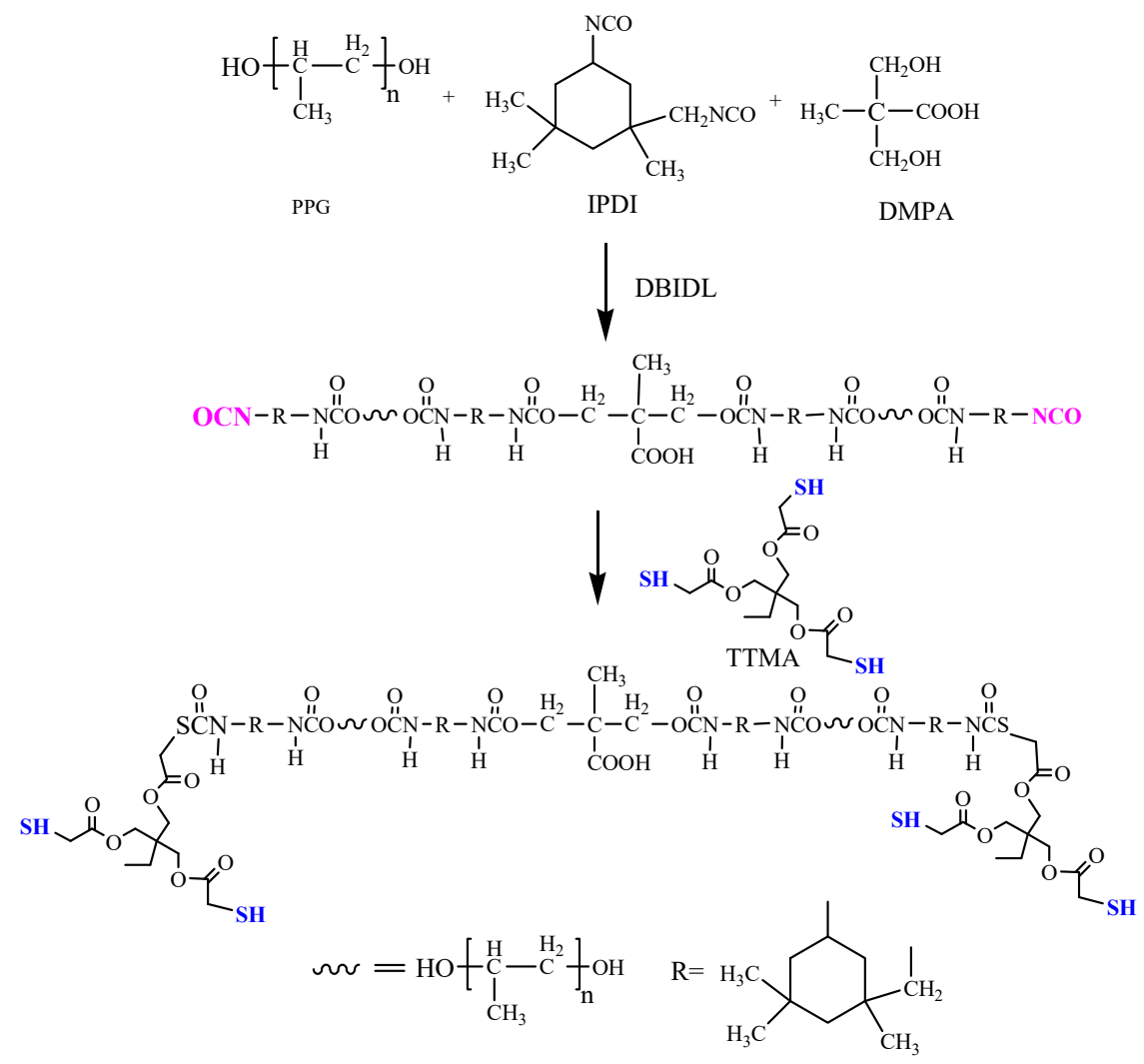

Scheme 1. The ideal diagram for the synthesis of Sulf-PU.

Table 2. The feed ratios for the preparation of sulfhydryl-terminated polyurethanes (Sulf-PUs).

\begin{tabular}{cccccc}
\hline \multirow{2}{*}{ Sulf-PU } & \multirow{2}{*}{$\begin{array}{c}\text { The Molar Ratio } \\
\text { of NCO to OH }\end{array}$} & \multicolumn{4}{c}{ The Amount of the Raw Materials/mol } \\
\cline { 3 - 6 } & $2: 1$ & IPDI & DMPA & PPG-2000 & TTMA \\
\hline Sulf-PU-1 & $3: 1$ & 0.04 & 0.01 & 0.01 & 0.04 \\
Sulf-PU-2 & $4: 1$ & 0.06 & 0.01 & 0.01 & 0.08 \\
Sulf-PU-3 & $5: 1$ & 0.08 & 0.01 & 0.01 & 0.12 \\
Sulf-PU-4 & $6: 1$ & 0.1 & 0.01 & 0.01 & 0.16 \\
Sulf-PU-5 & $7: 1$ & 0.12 & 0.01 & 0.01 & 0.20 \\
Sulf-PU-6 & 0.14 & 0.01 & 0.01 & 0.24 \\
\hline
\end{tabular}

\subsection{Synthesis of Allyl-Terminated Hyperbranched Polycarbosilanes}

Various generations of allyl-terminated hyperbranched polycarbosilanes shown in Figure S2 were synthesized according to the procedure given by Scheme S1. The ${ }^{1} \mathrm{H}-\mathrm{NMR}$ and ${ }^{13} \mathrm{C}-\mathrm{NMR}$ spectra of the allyl terminated hyperbranched polycarbosilanes were exhibited in Figure S3 and Figure S4 respectively.

\subsection{Preparation of Ultraviolet (UV)-Cured Coatings}

The mixtures of sulf-PU and allyl-terminated hyperbranched polycarbosilane were deposited on slides with thickness about $0.5 \mathrm{~mm}$ by spin-coating under a rotation speed of $3000 \mathrm{r} / \mathrm{s}$ for $30 \mathrm{~s}$, and then cured by UV (ZB1000, Changzhou Zibo Electron Technology Co., Ltd., Changzhou, China) with laser wavelength $365 \mathrm{~nm}$, radiation Intensity $10.6 \mathrm{mw} \cdot \mathrm{cm}^{-2}$, and a distance of the slides to the light of 
$20 \mathrm{~cm}$. A typical procedure for preparation UV-cured coatings, sulf-PU-4 mixtured with G2 according to molar ratio of 3-mercaptopropyl to acrylate with 2:1 and cured for $40 \mathrm{~s}$.

\subsection{Characterization}

The ${ }^{1} \mathrm{H}$ nuclear magnetic resonance (NMR) spectrum was recorded on a Bruker AVANCE AV400 (400 MHz) (Bruker, Billerica, MA, USA) spectrometer in $\mathrm{CDCl}_{3}$ at room temperature without tetramethylsilane (TMS) as internal reference. FT-IR analysis was carried out using a Nicolet 700 spectrometer (Nicolet Co., Ltd., Madison, WI, USA) over the frequency range $4000-650 \mathrm{~cm}^{-1}$ with ATR attachment. The pencil hardness of the cured samples was measured with a BGD-562 Pencil hardness meter (Zhenwei Testing Machinery Co Ltd, Jiangdu, China) according to GBT6739-2006. Thermogravimetric analysis (TGA) was carried out using a TG 209C apparatus (NETZSCH-Gerätebau $\mathrm{GmbH}$, Selb, Germany), in which samples were heated from ambient temperature to $800{ }^{\circ} \mathrm{C}$ at a rate of $10^{\circ} \mathrm{C} \mathrm{min}-1$ in a nitrogen atmosphere. The cured samples were washed with toluene by Soxhlet extration at $150{ }^{\circ} \mathrm{C}$ for $4 \mathrm{~h}$ and then the degree of curing contents were calculated as a percentage of the residual mass in the original mass of the cured coatings. The adhesion was measured with a BGD-502 paint film according to ISO 2409-2007 by a cross cut test (see Table S1). The water absorption was measured after the coatings were immersed in water for $24 \mathrm{~h}$ according to "Determination of water absorption rate of insullac films" HGT 3856-2006. The surface water contact angle was measured according to "Measurement of water-contact angle of plastic films", GB/T 30693-2014 on a KRUSS DSA30 water contact angle meter (KRÜSS, Hamburg, Germany).

\section{Results and Discussion}

\subsection{The Influence of Curing Time}

The influence of curing time on the performances of the coatings prepared is summarized in Table 3. When the curing time was in the range of $10-40 \mathrm{~s}$, the degree of curing content, pencil hardness and surface water contact angle of the coatings increased while the water absorption of the coatings decreased with the increase of the curing time. A further increment of the curing time had almost no effect on these properties of the coatings, which may be explained by the fact that the mixture was cured completely by UV for $40 \mathrm{~s}$. This is proved by the FT-IR spectra of the cured films shown by Figure 1 . The characteristic vibration absorption peak of $C=C$ in the allyl group at $1627 \mathrm{~cm}^{-1}$ disappeared and the weak characteristic absorption peak of HS at $2550 \mathrm{~cm}^{-1}$ becomes smaller and smaller with the prolongation of the curing time and vanished when the curing time is $40 \mathrm{~s}$. The coatings prepared exhibit hydrophobic properties because the contact angle of water is greater than $90^{\circ}$. The coatings show fairly low water absorption in the range of $0.59-1.36 \mathrm{w} t \%$, which is lower than the traditional UV-cured PU coatings [21]. This is consistent with the coatings reported previously that the high contact angle of water results in low water absorption [22,23].

Table 3. The influence of curing time on the silicone coatings prepared.

\begin{tabular}{cccccc}
\hline Entry & $\begin{array}{c}\text { Curing } \\
\text { Time/s }\end{array}$ & $\begin{array}{c}\text { Degree of } \\
\text { Curing } \\
\text { Content } / \%\end{array}$ & $\begin{array}{c}\text { Pencil } \\
\text { Hardness }\end{array}$ & $\begin{array}{c}\text { Surface Water } \\
\text { Contact } \\
\text { Angle/ }\end{array}$ & $\begin{array}{c}\text { Water } \\
\text { Absorption/(wt\%) }\end{array}$ \\
\hline 1 & 10 & 63.0 & $5 \mathrm{~B}$ & 89.6 & 1.36 \\
2 & 20 & 72.8 & $2 \mathrm{~B}$ & 93.2 & 1.06 \\
3 & 30 & 82.0 & $\mathrm{~B}$ & 95.8 & 0.75 \\
4 & 40 & 85.6 & $\mathrm{HB}$ & 102.2 & 0.60 \\
5 & 50 & 85.8 & $\mathrm{HB}$ & 102.1 & 0.62 \\
6 & 60 & 86.2 & HB & 102.8 & 0.59 \\
\hline
\end{tabular}

Conditions: sulf-PU was the sulf-PU-4 in the Table 2 and allyl-terminated hyperbranched polycarbosilane was G2. The molar ratio of 3-mercaptopropyl to acrylate is 2:1. The water absorption was measured after the coatings being immersed in water for $24 \mathrm{~h}$. 


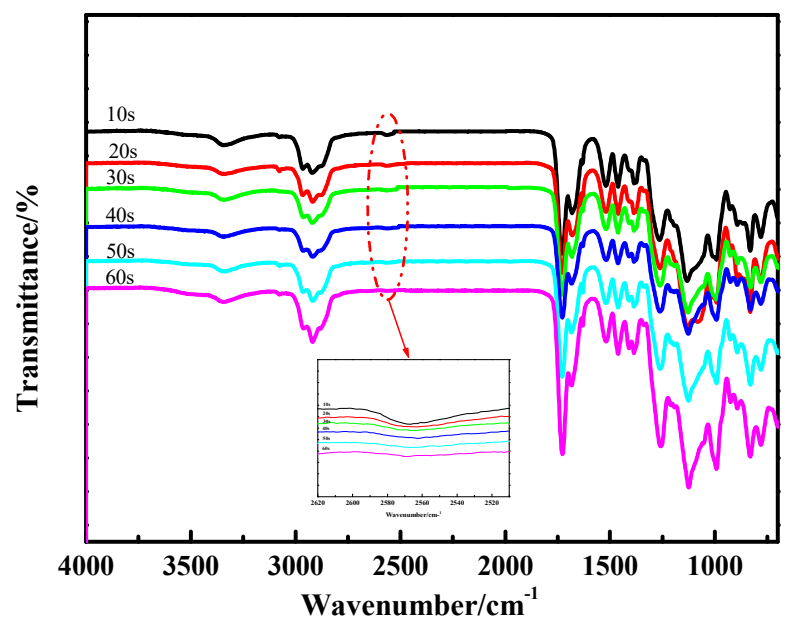

Figure 1. The Fourier transform infrared (FT-IR) spectra of the films cured for various periods.

Sulf-PU was the sulf-PU-4 in Table 1 and allyl-terminated hyperbranched polycarbosilane was G2. The molar ratio of 3-mercaptopropyl to acrylate is 2:1.

\subsection{The Influence of Various Sulf-PUs}

The influence of various sulf-PUs (In Table 2) was investigated and the results were collected in Table 4. It can be seen that the pencil hardness of the coatings is the highest when the coating is prepared with sulf-PU-4 and the pencil hardness of all the coatings prepared is in the range of 5B-HB, which is similar to those UV-cured polyurethane coatings reported previously [24-26]. The surface water contact angle is still not very high, which is in the range of 88.5-102.2 ${ }^{\circ}$ (Figure S5). The water absorption is in the range of $0.73-1.06 \mathrm{wt} \%$, which denotes the coating prepared with fairly low water absorption.

Table 4. The influence of various sulf-PUs on the cure materials.

\begin{tabular}{ccccc}
\hline Entry & Sulf-PU & $\begin{array}{c}\text { The Pencil } \\
\text { Hardness }\end{array}$ & $\begin{array}{c}\text { The Surface Water } \\
\text { Contact Angle/ }\end{array}$ & $\begin{array}{c}\text { Water } \\
\text { Absorption/(wt\%) }\end{array}$ \\
\hline 1 & Sulf-PU-1 & 5B & $88.5^{\circ}$ & 1.06 \\
2 & Sulf-PU-2 & 3B & 93.4 & 0.95 \\
3 & Sulf-PU-3 & 3B & 95.1 & 0.97 \\
4 & Sulf-PU-4 & HB & 102.2 & 0.60 \\
5 & Sulf-PU-5 & 2B & 96.4 & 0.70 \\
6 & Sulf-PU-6 & 2B & 96.8 & 0.73 \\
\hline
\end{tabular}

Conditions: Allyl-terminated hyperbranched polycarbosilane was G2. The molar ratio of 3-mercaptopropyl to allyl is $2: 1$. The coatings were cured for $40 \mathrm{~s}$. The water absorption was measured after the coatings were immersed in water for $24 \mathrm{~h}$.

As reported by previous work, the conventional PU coatings have poor heat resistance which will undergo severe pyrolysis when the temperature exceeds $200{ }^{\circ} \mathrm{C}$ [9-11]. To investigate the thermal stability of the UV-cured coatings obtained, the materials prepared with various sulf-PUs were analyzed by TGA (Figure 2). As can be seen from the TGA curves presented in Figure 2, the initial decomposition temperature $\left(\mathrm{T}_{\mathrm{d}} 5 \%\right)$ ranges from $258^{\circ} \mathrm{C}$ to $268^{\circ} \mathrm{C}$, which is obviously much higher than those of the conventional PU coatings reported [9-11]. 


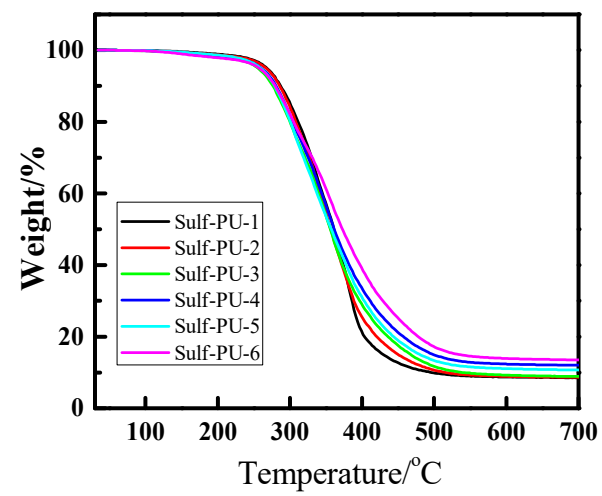

Figure 2. Thermogravimetric analysis (TGA) curves of the coatings prepared with various of sulf-PUs.

\subsection{The Influence of Molar Ratio of 3-Mercaptopropyl to Allyl}

The influence of the molar ratio of 3-mercaptopropyl to allyl on the UV-cured coatings is shown in Table 5. It can be seen that the pencil hardness of the coatings was in the range of $4 \mathrm{~B}-\mathrm{HB}$, which was obviously effected by the molar ratio of 3-mercaptopropyl to allyl. When the molar ratio of 3-mercaptopropyl to allyl is 1.4, the pencil hardness and surface water contact angle of the coating is the highest (Figure S6), which may be ascribed to the highest cross-linking density [16]. The water absorption is in the range of $0.60-1.03 \mathrm{wt} \%$, which still remains quite low.

Table 5. The influence of molar ratio of 3-mercaptopropyl to allyl on the cure materials.

\begin{tabular}{ccccc}
\hline Entry & $\begin{array}{c}\text { Molar ratio of } \\
\text { 3-Mercaptopropyl } \\
\text { to Allyl }\end{array}$ & Pencil Hardness & $\begin{array}{c}\text { Surface Water } \\
\text { Contact Angle/ }\end{array}$ & $\begin{array}{c}\text { Water } \\
\text { Absorption/(wt\%) }\end{array}$ \\
\hline 1 & 0.8 & $4 \mathrm{~B}$ & 85.5 & 1.03 \\
2 & 1.0 & $3 \mathrm{~B}$ & 91.4 & 0.87 \\
3 & 1.2 & B & 96.8 & 0.64 \\
4 & 1.4 & HB & 102.2 & 0.60 \\
5 & 1.6 & 2B & 87.1 & 0.75 \\
6 & 1.8 & 3B & 72.1 & 0.82 \\
\hline
\end{tabular}

Conditions: sulf-PU was the sulf-PU-4 in the Table 2 and allyl-terminated hyperbranched polycarbosilane was G2. The coatings were cured for $40 \mathrm{~s}$. The water absorption was measured after the coatings being immersed in water for $24 \mathrm{~h}$.

\subsection{The Influence of Generations of Allyl-Terminated Hyperbranched Polycarbosilanes}

The influence of generations of allyl-terminated hyperbranched polycarbosilanes was explored as shown in Table 6, and the generations of allyl-terminated hyperbranched polycarbosilanes have significant impact on the pencil hardness of the silicone coatings. The pencil hardness of the coating is the highest when the generation of the hyperbranched polycarbosilanes is G2. A preferable generation of the hyperbranched polycarbosilanes will result in an optimal cross linking network of the molecular structure, which may be attributed to the optimal cross-linking density [27]. 
Table 6. The influence of generations of allyl-terminated hyperbranched polycarbosilanes.

\begin{tabular}{ccccc}
\hline Entry & $\begin{array}{c}\text { Generations of } \\
\text { Allyl-Terminated } \\
\text { Hyperbranched } \\
\text { Polycarbosilanes }\end{array}$ & Pencil Hardness & $\begin{array}{c}\text { Surface Water } \\
\text { Contact Angle/ }\end{array}$ & $\begin{array}{c}\text { Water Absorpti } \\
\text { on/(wt\%) }\end{array}$ \\
\hline 1 & G0 & $5 B$ & 75.8 & 1.07 \\
2 & G1 & 3B & 87.9 & 0.64 \\
3 & G2 & HB & 102.2 & 0.60 \\
4 & G3 & B & 98.2 & 0.63 \\
\hline
\end{tabular}

Conditions: sulf-PU was the sulf-PU-4 in the Table 2 and The molar ratio of 3-mercaptopropyl to allyl is 2:1. The coatings were cured for $40 \mathrm{~s}$. The water absorption was measured after the coatings were immersed in water for $24 \mathrm{~h}$.

Figure 3 shows the TGA curves of UV-cured silicone modified coatings with various generations of allyl-terminated hyperbranched polycarbosilanes. As can be seen, the start thermal decomposition temperature $\left(\mathrm{T}_{\mathrm{d}} 5 \%\right)$ of the cured coatings is in the range of $248-263{ }^{\circ} \mathrm{C}$. It also can be concluded that the UV-cured coatings with various generations of allyl-terminated hyperbranched polycarbosilanes have good thermal stability, which is obviously higher than those of the conventional PU coatings reported [9-11].

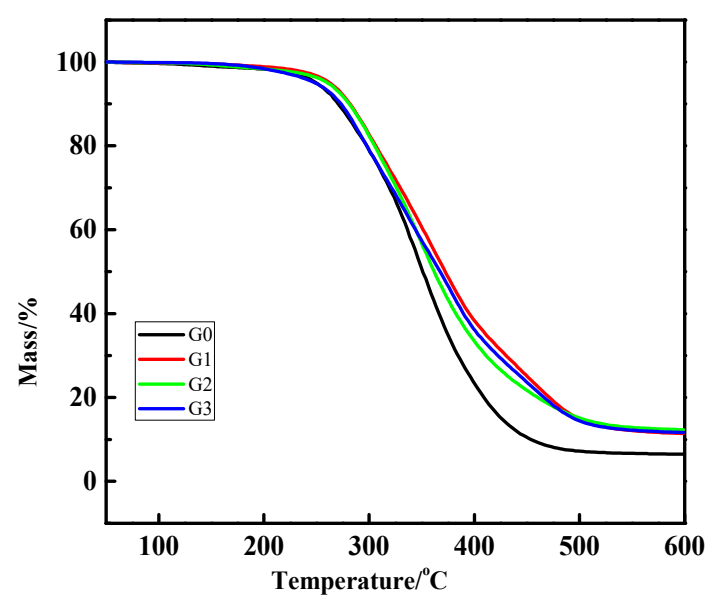

Figure 3. TGA curves of the coatings prepared with various generations of allyl-terminated hyperbranched polycarbosilanes.

\subsection{The Adhesive Properties}

The adhesion properties of the coating on various substrates were measured with a BGD-502 paint film according to GB/T 9286-88 by a cross cut test as shown by Table 7 and Figure 4 . The coatings obtained exhibit grade 1 (Figure 4a), grade 2 (Figure 4 b) and grade 3 (Figure $4 c$ ), adhesion to the glass, tin plate and aluminum sheet, respectively. When it comes to the coating on glass, although there is a little slice separation, the separated area is obviously no more than $5 \%$. The coating partially peels off the tin plate in the test area and the adhesion of the coating on the aluminum sheet is worst because a large area of coating falls off in the test area. This denotes that the UV-cured materials obtained can be used as coating for substrates such as glass and tin plate, but not suitable for aluminum.

Table 7. The adhesive properties of the coatings on various substrates.

\begin{tabular}{cccc}
\hline Substrates & Glass Slide & Tin plate & Aluminum Sheet \\
\hline Adhesive grade & Grade 1 & Grade 2 & Grade 3 \\
\hline
\end{tabular}




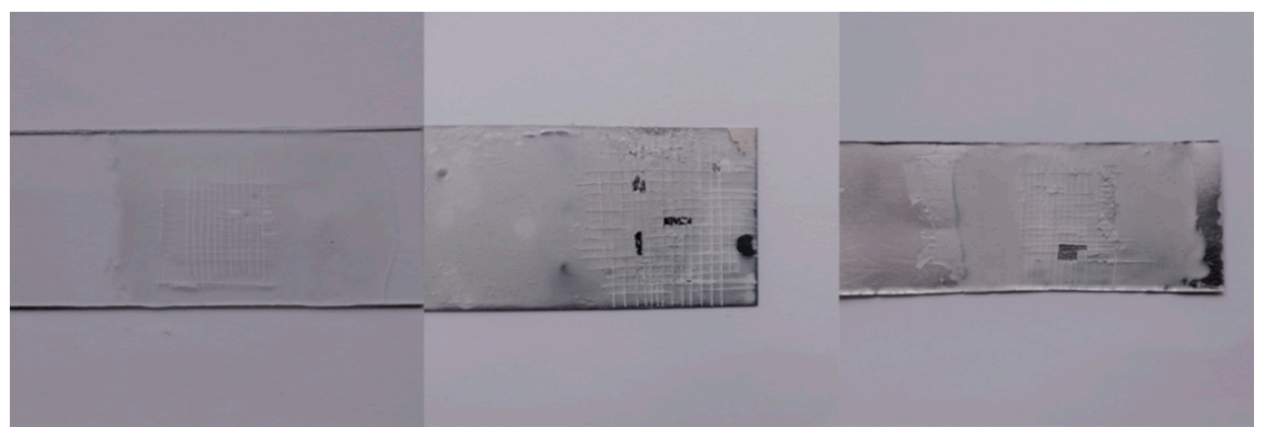

(a)

(b)

(c)

Figure 4. The photos for the adhesive experiments of the coatings on various substrates. (a) Glass slide; (b) tin plate; (c) aluminum sheet.

\section{Conclusions}

To overcome the shortcoming of poor heat resistance for conventional PU coatings, UV-cured solvent-free hyperbranched polycarbosilane modified PU coatings were prepared by sulfhydrylterminated polyurethanes and allyl-terminated hyperbranched polycarbosilanes. The coatings show fairly low water absorption in the range of $0.6-1.36 \mathrm{wt} \%$. The coatings obtained exhibit grade 1, grade 2 and grade 3 adhesion to glass, tin plate and aluminum sheet, respectively. This denotes that the UV-cured materials obtained can be used as coating for substrates such as glass and tin plate, but are not suitable for aluminum. When sulf-PU-4 was mixed with G2 according to a molar ratio of 3-mercaptopropyl to acrylate of 2:1 and cured for $40 \mathrm{~s}$, initial decomposition temperature ( $\mathrm{T}_{\mathrm{d}} 5 \%$ ) of the UV-cured coating was $268^{\circ} \mathrm{C}$ and water absorption was $0.60 \mathrm{wt} \%$. Compared with the conventional PU coatings with decomposition temperature lower than $200{ }^{\circ} \mathrm{C}$, the hyperbranched polycarbosilane-modified PU coatings prepared show obvious superior thermal stability. This implies that modification of PU with hyperbranched polycarbosilanes may be an effective method to improve the thermal stability of PU.

Supplementary Materials: The following are available online at http://www.mdpi.com/2079-6412/10/4/350/s1, Figure S1: FT-IR analysis of Sulf-PU; Figure S2: The structure of various generations for allyl terminated hyperbranched polycarbosilanes; Figure S3: The ${ }^{1} \mathrm{H}-\mathrm{NMR}$ spectra of various generation of allyl terminated hyperbranched polycarbosilanes; Figure S4: ${ }^{13} \mathrm{C}-\mathrm{NMR}$ spectra of of various generation of allyl terminated hyperbranched polycarbosilanes; Figure S5: Photos for the surface water contact angle of coatings prepared with various of Sulf-PUs; Figure S6: Photos for the surface water contact angle of coatings prepared with various of molar ratio of 3-mercaptopropyl to allyl; Table S1: The adhesion grade, corresponding peel off ratio and sample drawings; Scheme S1: The scheme for the synthesis of various generations allyl terminated hyperbranched polycarbosilanes;Scheme S2. Scheme of the cross-linking reaction of G2 with Sulf-PU.

Author Contributions: Conceptualization, X.Y.; formal analysis X.J., T.Z., F.C. and X.Y.; investigation, X.J., Y.F., J.L.; data curation, X.J., J.L. and Y.W.; writing-Original draft preparation, X.Y.; writing-Review and editing, X.Y.; project administration, G.L. and X.Y.; funding acquisition, X.Y. All authors have read and agreed to the published version of the manuscript.

Funding: This research was funded by Zhejiang Provincial Natural Science Foudation of China, grant number LY14E030008 and the Open Fund of the Collaborative Innovation Centre for Fluorosilicon Fine Chemicals and Materials Manufacturing of Zhejiang Province, grant number FSi2019A007.

Conflicts of Interest: The authors declare no conflict of interest.

\section{References}

1. Boton, L.; Puguan, J.M.; Latif, M.; Kim, H. Synthesis and properties of quick-drying UV-curable hyperbranched waterborne polyurethane coating. Prog. Org. Coat. 2018, 125, 201-206. [CrossRef]

2. Wei, D.D.; Liao, B.; Yong, Q.W.; Li, T.; Wang, H.Y.; Huang, J.H.; Pang, H. Castor oil based hyperbranched urethane acrylates and their performance as UV-curable coatings. J. Macromol. Sci. Part A Pure Appl. Chem. 2018, 55, 422-432. [CrossRef] 
3. Cheng, C.; Zhang, X.; Huang, Q.; Dou, X.; Li, J.; Cao, X.; Tu, Y. Preparation of fully bio-based UV-cured non-is Cyanate polyurethanes from ricinoleic acid. J. Macromol. Sci. A 2015, 52, 485-491. [CrossRef]

4. Ahmed, A.; Sarkar, P.; Ahmad, I.; Das, N.; Bhowmick, A.K. Influence of the nature of acrylates on the reactivity, structure, and properties of polyurethane acrylates. Ind. Eng. Chem. Res. 2015, 54, 47-54. [CrossRef]

5. Wu, Y.F.; Liu, J.L.; Jiao, X.J.; Cheng, F.; Lai, G.Q.; Yang, X.F. UV cured transparent flexible silicone materials with high tensile strength. ACS Omega 2020, 5, 6199-6206. [CrossRef]

6. Daniel, D.L.; Rubén, S.R.; Juan, C.G.Q.; Ignacio, M.G. Custom-made chemically modified graphene oxide to improve the anti-scratch resistance of urethane-acrylate transparent coatings. Coatings 2019, 9, 408.

7. Kumar, R.; Yadav, R.; Kolhe, M.A.; Bhosale, R.S.; Narayan, R. 8-Hydroxypyrene- 1,3,6-trisulfonic acid trisodium salt (HPTS) based high fluorescent, $\mathrm{pH}$ stimuli waterborne polyurethane coatings. Polymer 2018, 136, 157-165. [CrossRef]

8. Lorena, E.S.C.; Gilles, T.; Xavier, C.; Zeferino, G.A. Solvolysis of acrylate-urethane coatings cured by electron-beam and UV radiation. Prog. Org. Coat. 2019, 136, 105268.

9. Mishra, A.K.; Narayan, R.; Aminabhavi, T.M.; Pradhan, S.K.; Raju, K.V.S.N. Hyperbranched polyurethane (HBPU)-urea and HBPU-imide coatings: Effect of chain extender and NCO/OH ratio on their properties. Prog. Org. Coat. 2012, 74, 134-141. [CrossRef]

10. Bing, H.; Lin, Y. Highly heat-resistant silicon-containing polyurethane-imide copolymers: Synthesis and thermal mechanical stability. Eur. Polym. J. 2017, 91, 337-353.

11. Pagacz, J.; Hebdab, E.; Janowskic, B.; Sternikd, D.; Janciab, M.; Pielichowskib, K. Thermal decomposition studies on polyurethane elastomers reinforced with polyhedral silsesquioxanes by evolved gas analysis. Polym. Degrad. Stabil. 2018, 149, 129-142. [CrossRef]

12. Wei, D.D.; Huang, X.M.; Zeng, J.J.; Deng, S.L.; Xu, J.H. Facile synthesis of a castor oil-based hyperbranched acrylate oligomer and its application in UV-curable coatings. J. Appl. Polym. Sci. 2020, e49054. [CrossRef]

13. Luke, A.B.; Lisa, M.R.; James, R.D.; Kathleen, S.C.; Pavel, N.; Michael, K.C.; Hilmar, K.; Matthew, J.D.; Matthew, B.D. Synthesis of a two-component carbosilane system for the advanced manufacturing of polymer-derived ceramics. Chem. Mater. 2018, 30, 7527-7534.

14. Hiroshi, Y.; Yoshitada, S.; Tumula, V.R.; Yuko, U. Synthesis and electr Chemical, optical, and thermal properties of polycarbosilanes with silyleneevinyleneephenyleneevinylene backbones and triphenylamine or carbazole unit-containing side chains. J. Organomet. Chem. 2012, 710, 59-67.

15. Liu, X.X.; Rathore, S.J.; Dubois, G.; Interrante, L.V. Grignard condensation routes to 1,3-disilacyclo butane-containing cyclolinear polycarbosilanes. J. Polym. Sci. Part A Polym. Chem. 2017, 55, 1547-1557. [CrossRef]

16. Mirshahi, F.; Bastani, S.; Sari, M.G. Studying the effect of hyperbranched polymer modification on the kinetics of curing reactions and physical/mechanical properties of UV-curable coatings. Prog. Org. Coat. 2016, 90, 187-199. [CrossRef]

17. Zhang, D.H.; Liu, C.H.; Chen, S.F.; Zhang, J.H.; Cheng, J.; Miao, M.H. Highly efficient preparation of hyperbranched epoxy resins by UV-initiated thiol-ene click reaction. Prog. Org. Coat. 2016, 101, 178-185. [CrossRef]

18. Duan, Q.; Wang, S.Y.; Wang, Q.F.; Li, T.; Chen, S.F.; Miao, M.H.; Zhang, D.H. Simultaneous improvement on strength, modulus, and elongation nanotube films functionalized by hyperbranched polymers. ACS Appl. Mater. Interfaces 2019, 11, 36278-36285. [CrossRef]

19. Cheng, J.; Wang, S.Q.; Zhang, J.H.; Miao, M.H.; Zhang, D.H. Influence of vinyl-terminated hyperbranched polyester on performance of films obtained by UV-initiated thiol-ene click reaction of $\mathrm{A}_{2}+\mathrm{B}_{3}$ system. J. Coat. Technol. Res. 2018, 15, 1049-1057. [CrossRef]

20. Resetco, C.; Hendriks, B.; Badi, N.; Prez, F.D. Thiol-ene chemistry for polymer coatings and surface modification-building in sustainability and performance. Mater. Horiz. 2017, 4, 1041-1053. [CrossRef]

21. Mishra, V.; Desai, J.; Patel, K.I. (UV/Oxidative) dual curing polyurethane dispersion from cardanol based polyol: Synthesis and characterization. Ind. Crop. Prod. 2018, 111, 165-178. [CrossRef]

22. Wu, S.; Hayakawa, T.; Kikuchi, R.; Grunzinger, S.; Kakimoto, M. Synthesis and characterization of Semiaromatic polyimides containing POSS in Main chain derived from double-Decker-shaped Silsesquioxane. Macromolecules 2007, 40, 5698-5705. [CrossRef] 
23. Liang, S.Y.; Xu, K.; Liu, H.B.; Gui, X.F.; Zhang, T. Preparation and characterization of dimer fatty acid epoxy-acrylate resin hybrid emulsion for phot Curable coatings. Colloid Polym. Sci. 2019, 297, 1199-1211. [CrossRef]

24. Fu, J.C.; Wang, L.; Yu, H.J.; Haroon, M.; Haq, F.; Shi, W.L.; Wu, B.; Wang, L.B. Research progress of UV-curable polyurethane acrylate-based hardening coatings. Prog. Org. Coat. 2019, 131, 82-99. [CrossRef]

25. Flores, M.; Fernandez-Francos, X.; Ramis, X.; Sangermano, M.; Ferrando, F.; Serra, A. Phot Curing of cycloaliphatic epoxy formulations using polyesters with multiarm star topology as additives. J. Appl. Polym. Sci. 2014, 131, 596-602. [CrossRef]

26. Dai, J.; Liu, X.; Ma, S.; Wang, J.; Shen, X.; You, S.; Zhu, J. Soybean oil-based UVcurable coatings strengthened by crosslink agent derived from itaconic acid together with 2-hydroxyethyl methacrylate phosphate. Prog. Org. Coat. 2016, 97, 210-215. [CrossRef]

27. Miao, J.T.; Yuan, L.; Guan, Q.B.; Liang, G.Z.; Gu, A.J. Water-phase synthesis of a biobased allyl compound for building UV-curable flexible thiol-ene polymer networks with high mechanical strength and transparency. ACS Sustain. Chem. Eng. 2018, 6, 7902-7909. [CrossRef]

(C) 2020 by the authors. Licensee MDPI, Basel, Switzerland. This article is an open access article distributed under the terms and conditions of the Creative Commons Attribution (CC BY) license (http://creativecommons.org/licenses/by/4.0/). 